\title{
Calculation of Limits of Fire Resistance for Structures with Fire Retardant Coating
}

\author{
Artem Krivtcov ${ }^{1, a}$, Marina Gravit ${ }^{1}$, Sergei Zimin ${ }^{1}$, Oleg Nedryshkin ${ }^{1}$ and Valerii Pershakov ${ }^{2}$ \\ ${ }^{1}$ Peter the Great St. Petersburg Polytechnic University, 195251, 29, Politekhnicheskaya st., Russia \\ ${ }^{2}$ National Aviation University, Kosmonavta Komarova Ave, 1, Kiev, Ukraine, 03680
}

\begin{abstract}
This article is devoted to fireproof processing of steel structures. The main task is to consider different types of sections of rod elements and to choose the most effective section for a steel column from the point of view of fire protection. For the solution of this task the steel columns with various cross sections working in identical entry conditions were considered. All necessary calculations for all types of sections were carried out. Results of calculations were presented in the summary table according to which the comparative analysis was made. At the end of work the conclusion that the compound section from four equal corners is the most effective from the point of view of fire protection.
\end{abstract}

\section{Introduction}

Building constructions, including steel are used widely because of the opportunities that they give to various objectives. Steel is often used in construction due to a wonderful combination of technological and operational properties, exemplified by many unique architectural constructions in the world. However, there is an important problem, with which humanity faced since its inception - fire protection. The main objective in this protection is to achieve security of people in the building. The second most important task is the preservation of wealth that can be lost in a fire. Many studies, standards, numerous tests of materials and structures are devoted to this problem. However, because of the importance of this problem and the development of technology, the relevance of the fire safety and search for new technical solutions in this area are retained $[1,2,16]$.

Due to the numerous technical solutions and requirements for steel structures, it is difficult to expect the same solutions for different constructions. Firstly, the solution of fire protection of steel structures considers a number of factors the importance of which often depends on the function of construction. Therefore, it is important to determine the fundamental criteria that define the ways of fire protection of steel structures $[6,14]$.

The main task of this work was the calculation of the steel column in order to identify the most beneficial cross section in terms of fire protection. For this purpose in this paper was considered a fireproof material Knauf-Fireboard. The calculation was made according to the Russian regulations: Code Specification 16.13330.2011 "Steel Constructions", Federal Law of 22 July 2008 N 123-FZ "Technical Regulations on fire safety requirements".

\footnotetext{
${ }^{a}$ Corresponding author : artcomp2007@yandex.ru
} 
The rod element was an object of this research was. For practical application of this work the steel vertical columns working for the central compression were considered. Entry conditions on loading, a class of steel, length and conditions of fixing for all columns were identical, only cross sections were various. All columns were faced with the fireproof plate material Knauf-Fireboard.

Main objective of this work was comparison of necessary amount of fireproof material for rod elements of various cross sections. Golovanov V. I. researches were taken as a basis of this work [3, 4, $6,8,11,16]$. Also the results received in works $[9,12,18]$ were considered.

For the solution of an objective the following tasks were set:

- to carry out calculations of all considered sections on durability, stability and necessary thickness of fireproof material for these conditions;

- to carry out the comparative analysis and to draw conclusions on a consumption of metal and fireproof material depending on the cross section of a rod element.

\section{Description of the calculation}

\subsection{Fire retardant material}

The choice of materials for fire protection of steel structures is based on an understanding of their behaviour under high temperatures. It is important to know that some of the materials having good thermal properties can mechanically collapse from heat stress and thus not provide thermal protection. Others, however, having a flammability, but maintaining the mechanical stability under load during combustion (for example: wood), do not break down for some time and thus provide a barrier between the fire source and the structure. It is important to remember that the construction of the outer device fireproof cladding can significantly affect the fire resistance of a structure. The presence or appearance of fire-permeable holes can negate all the efforts of fireproofing [16].

In this paper material Knauf-Fireboard has been considered. It is a non-combustible plate materi-al developed by Knauf for fire safety of buildings.

Knauf-Fireboard is fire retardant facing material and is widely used in the finishing of technical premises, where, according to the fire safety requirements is necessary to use non-combustible materials, such as emergency exits of offices and shopping centers, evacuation routes. This product is also used in places where there is an increased risk of fire. Application of this material facilitates localization of fire in a room and preventing distribution of a flame outside [20, 22].

The difference between Knauf-Fireboard and other gypsum products is that the moisture evaporates from gypsum core after interaction with the flame, wherein the plate does not break or crack rather long time. Also plates Knauf-Fireboard have non-flammable fiberglass, which is a fire-resistant reinforcing frame product. Such reinforcing frame provides enhanced fire of entire structure [5, 17].

\subsection{Classification of buildings and structures according to fire danger}

The time of the fire cannot be infinite both because of the limited quantity of combustible material and due to the limited lifetime of constructions under fire exposure. Therefore, in Fire safety regula-tions for most constructions fire is normalized in the range of 0 to 6 hours [6].

Constructions separated into bearing and non-bearing have a significant difference in the required fire resistance. Therefore, different technical retardant solutions are used for them, although they can be made of a same steel assortment. For load-bearing elements an important factor is their responsibility for geometric variability of the structure under load during a fire, which can significantly reduce the critical temperature of steel. For non-bearing elements fire protection requirements are less stringent, as their role in ensuring the stability of the frame is negligible [12, 21].

Table 1 is a part of Table 21 from №123-FZ «Technical regulations for fire safety requirements» the main Russian regulation in fire safety. There are five fire classes of building in Russian regulations. In this paper, we considered only load-bearing structures in the building of the first fire class. 
Table 1. Compliance of fire class and fire-resistance of building constructions.

\begin{tabular}{|c|c|c|}
\hline \multirow{2}{*}{ Fire class of building } & \multicolumn{2}{|c|}{ Fire-resistance } \\
\cline { 2 - 3 } & load-bearing constructions & non-bearing constructions \\
\hline I & R120 & E30 \\
\hline II & R90 E15 \\
\hline III & R45 & E15 \\
\hline IV & R15 & E15 \\
\hline V & No regulations & No regulations \\
\hline
\end{tabular}

\subsection{Calculation of the fire-retardant treatment}

Steel for building structures has a high thermal conductivity, which significantly effects on structural fire protection engineering solutions. On one side elements of the steel structure heat up quickly, and the other - well distribute and dissipate heat. Balance of heat flows in heating and cooling determines the change in temperature of the structure and the time to reach the critical temperature $[10,13,15]$.

To make decisions on fire protection of steel structures two criteria were introduced: the given thickness of the metal and the critical temperature. The given thickness of metal allows consider the cross section of the steel profile and the nature of the heat supply in case of fire. Like every criterion the given thickness of metal involves some simplification, but for many practical solutions it is very useful $[12,19]$.

The given metal thickness is calculated by the formula:

$$
\delta=A_{n} / P
$$

where:

$A_{n}$ is cross sectional area, $\mathrm{cm}^{2}$;

$P$ is heated perimeter, $\mathrm{cm}$.

The heated perimeter value depends on the geometry of the cross section and is calculated according to the formulas in Table 3 of the Instruction for calculation of the actual limits of fire resistance of steel structures with flame-retardant facing made of plates Knauf-Fireboard, approved with EMERCOM Russia [11, 14].

This criterion shows how effective heat removal is in relation to heating depending on the shape of the cross section under the conditions of heating [7].

Another important criterion is the critical temperature. The fire resistance of steel structures occurs as a result of warming up their sections or parts of it to the critical temperature. The critical temperature of steel structures under a load depends on the type of design scheme of its bearing, the metal stamp and the value of the load $[8,9,14]$.

The critical temperature is defined as the lowest value of the two found in Table 1 of the Instruction for calculation of the actual limits of fire resistance of steel structures with flame-retardant facing made of plates Knauf-Fireboard, approved with EMERCOM Russia, depending on the values of the coefficients $\gamma_{t}$ and $\gamma_{e}$. Values of the coefficients $\gamma_{t}$ and $\gamma_{e}$, take into account changes in regulatory resistance and modulus of elasticity of steel.

Coefficient $\gamma_{t}$ is calculated by the formula:

$$
\gamma_{t}=N / A_{n} R_{y}
$$

where:

$N$ is longitudinal force, acting on the rod, $\mathrm{kg}$;

$R_{y}$ is calculated resistance of steel working on tensile, compression, bending in yield strength, $\mathrm{kg} / \mathrm{cm}^{2}$. 
Coefficient $\gamma_{e}$ is calculated by the formula:

$$
\gamma_{e}=N l_{0}^{2} / \pi^{2} E I_{\min }
$$

where:

$l_{0}$ - calculated length of the rod, $\mathrm{cm}$;

$I_{\text {min }}$ - minimal moment of inertia, $\mathrm{cm}^{4}$;

$E$ - modulus of elasticity of steel, $\mathrm{kg} / \mathrm{cm}^{2}$.

\section{Calculations}

\subsection{Input data}

An object of research is a vertical steel column with applied longitudinal force. The input data for the task is:

Class of fire resistance of the building: I;

Type of rod work: compression;

Type of fixing: fixing the ends;

Type of cladding and heating conditions: facing a box-shaped with 4 sides;

Longitudinal force: $90000 \mathrm{~kg}$;

Geometrical length of the rod: $300 \mathrm{~cm}$;

Grade of steel: C235;

The initial modulus of elasticity of steel: $2100000 \mathrm{~kg} / \mathrm{cm} 2$.

The task is to select cross sections satisfying the conditions of strength and stability and to calculate the necessary thickness of the plate material Knauf-Fireboard for each cross-section in the current input data.

\subsection{Types of used cross-sections}

In the calculation the most popular types of cross-sections were used: I-profiles, pipes, square profile, the composite section of the two channels, the composite sections of four equal corners.

\subsection{Calculation example}

\subsubsection{Characteristic of construction:}

Degree of fire resistance of the building: I.

In accordance with the Table 1: the fire resistance of structure is $120 \mathrm{~min}$.

\subsubsection{Characteristic of section:}

Cross-sectional view: Hot-rolled steel I-profile (GOST 8239-89) number 33.

In accordance with the assortment of metal, used in GOST 8239-89, geometrical characteristics of the section are presented in the Table 2 .

Table 2. Geometrical characteristics of the section.

\begin{tabular}{|c|c|c|c|}
\hline $\mathbf{h}, \mathbf{c m}$ & $\mathbf{b}, \mathbf{c m}$ & $\mathbf{A}_{\mathbf{n}}, \mathbf{c m}^{2}$ & $\mathbf{I}_{\min }, \mathbf{c m}^{\mathbf{4}}$ \\
\hline 33.0 & 14.0 & 53.8 & 419.0 \\
\hline
\end{tabular}




\subsubsection{Fire-retardant treatment}

Type of cladding and heating conditions: facing a box-shaped with 4 sides. In accordance with Table 3 of the Instruction for calculation of the actual limits of fire resistance of steel structures with flameretardant facing made of plates Knauf-Fireboard, approved with EMERCOM Russia, heated perimeter should be determined by the formula:

$$
\begin{gathered}
P=2 b+2 h \\
P=2 \cdot 14+2 \cdot 33 \\
P=94 \mathrm{~cm}
\end{gathered}
$$

Given metal thickness is calculated by the formula (1):

$$
\begin{gathered}
\delta=53.8 / 94 \\
\delta=0.572 \mathrm{~cm}
\end{gathered}
$$

Coefficient $\gamma_{t}$ is calculated by the formula (2):

$$
\begin{gathered}
\gamma_{t}=90000 / 53.8 \cdot 2250 \\
\gamma_{t}=0.74
\end{gathered}
$$

In accordance with Table 1 of the Instruction for calculation of the actual limits of fire resistance of steel structures with flame-retardant facing made of plates Knauf-Fireboard, approved with EMERCOM Russia, critical temperature:

$$
T_{c r}=344.18^{\circ} \mathrm{C}
$$

Coefficient $\gamma_{e}$ is calculated by the formula (3):

$$
\begin{gathered}
\gamma_{t}=90000 \cdot 150^{2} / 3.14 \cdot 2100000 \cdot 419 \\
\gamma_{t}=0.23
\end{gathered}
$$

In accordance with Table 1 of the Instruction for calculation of the actual limits of fire resistance of steel structures with flame-retardant facing made of plates Knauf-Fireboard, approved with EMERCOM Russia, critical temperature:

$$
T_{c r}=898.28^{\circ} \mathrm{C}
$$

So the minimal critical temperature:

$$
T_{c r}=344.18^{\circ} \mathrm{C}
$$

In accordance with the Instruction for calculation of the actual limits of fire resistance of steel structures with flame-retardant facing, approved with EMERCOM Russia, the minimum allowable thickness of Knauf-Fireboard in these conditions is $32,5 \mathrm{~mm}$.

\section{Results}

\subsection{Result of calculation for different cross-sections}


The results of calculation for different cross-sections are presented in the Table 3.

Table 3. Results of calculation for different cross-sections.

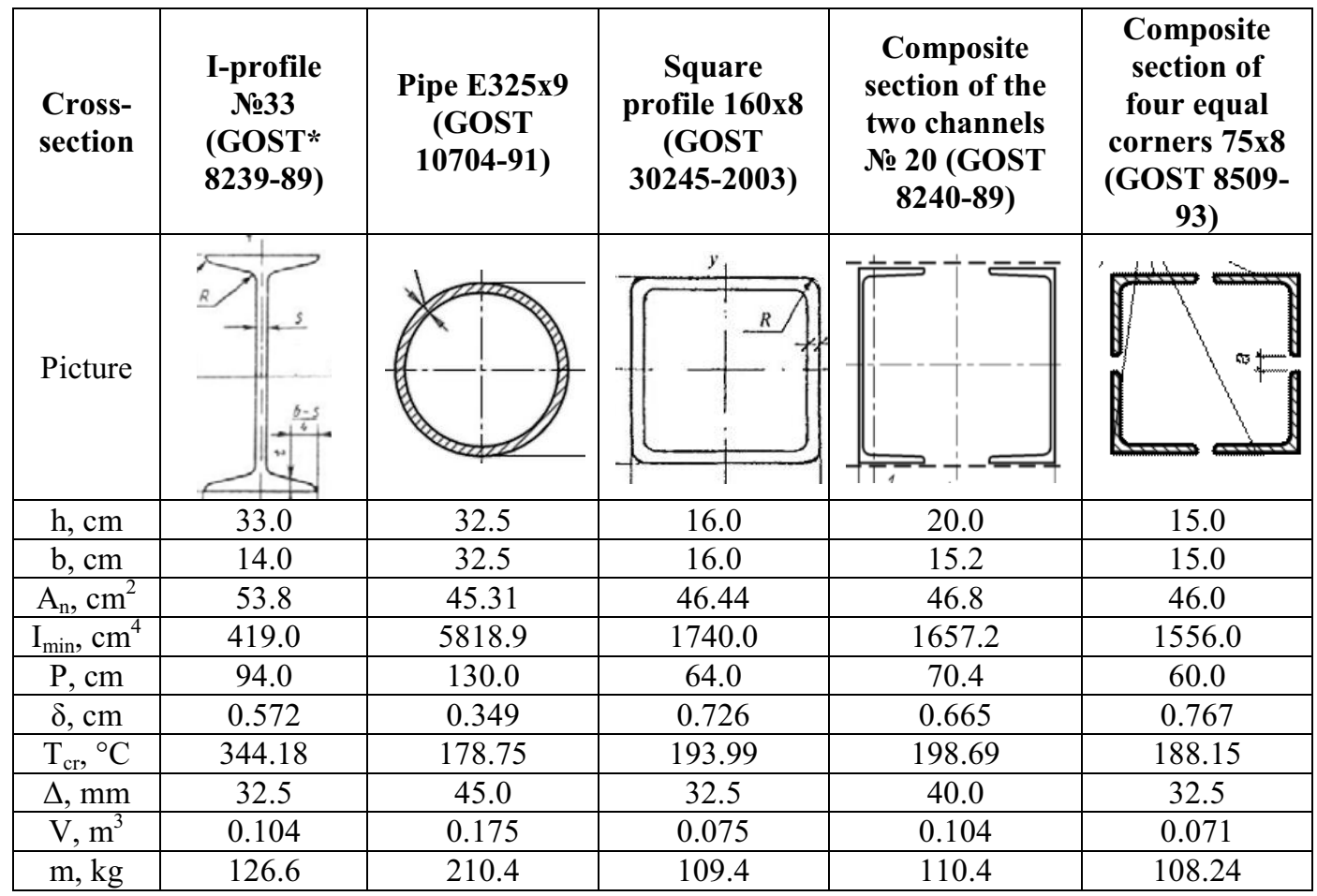

where:

$\Delta, \mathrm{mm}$ - minimum allowable thickness of Knauf-Fireboard;

$\mathrm{V}, \mathrm{m}^{3}$ - total volume of Knauf-Fireboard for a column;

$\mathrm{m}, \mathrm{kg}$ - total weight of a column.

*GOST - National Standart of Russian Federation.

\subsection{Conclusions by results of calculations}

After the made calculation it is possible to draw the following conclusions:

- As a result of calculating a cross-section consisting of four equal corners proved the most costeffective in terms of the consumption of fireproof material. This section of the column other conditions being equal has the least amount of material Knauf-Fireboard $-0.071 \mathrm{~m}^{3}$. Also, this section is the most advantageous in terms of the consumption of metal in the column -108.24 $\mathrm{kg}$.

- Also very economical with both points of view turned cross-section of the square profile. Material consumption Knauf-Fireboard appeared $0.075 \mathrm{~m}^{3}$, and steel consumption was slightly higher than that of the cross-section of four equal corners $-109.4 \mathrm{~kg}$.

- The least advantageous in terms of consumption of steel and fire retardant turned cross-section of the pipe $\left(0.175 \mathrm{~m}^{3}, 210.4 \mathrm{~kg}\right)$. Arranging conditions of stability and strength cross-section was too large, leading to a waste of material. 


\section{Conclusions}

The purpose of this work was to reveal the most effective from the point of view of fire protection the cross section of a steel rod element. By the results of conducted research the following conclusions were drawn:

- calculation of the cross sections of steel rod elements which are the most used today was made;

- as a result of calculation by the most effective from the point of view of a consumption of fireproof material there were sections from four equal corners and a square profile.

\section{References}

1. M. Lazarevska, M. Cvetkovska, M. Knežević, A. Trombeva Gavriloska, M. Milanovic, V. Murgul, N. Vatin, Applied Mechanics and Materials, 627, 276-282 (2014)

2. M. Lazarevska, M. Knežević, M. Cvetkovska, A. Trombeva-Gavriloska, Tehnicki Vjesnik, 21 (6), 1353-1359 (2014)

3. V. Golovanov, V. Pavlov, A. Pekhotikov. Pozharnaya bezopasnost, 3, 48-58 (2002)

4. Yu. Morozov, L. Efron, O. Chevskaya, N. Shtychkov, P. Odesskiy, D. Solovyev, V. Moskalenko, A. Stepashin, I. Shabalov, D. Kulik. Stal, 9, 48-53 (2004)

5. M. Jevrić, M. Knežević, J. Kalezić, N. Kopitović-Vuković, I. Ćipranić, Tehnicki Vjesnik, 21 (4), 873-879 (2014)

6. B. Parlour. Fire safety, 5, 18-19 (2004)

7. O. Lamkin, M. Gravit, O. Nedryshkin. Construction of Unique Buildings and Structures, 11(38), 42-58 (2015)

8. V. Strakhov, A. Garashchenko, G. Kuznetsov, V. Rudzinskii. Combustion, explosion, and shock waves, 2, 212-220 (2001)

9. M. Gravit. Fire and Explosion Safety, 11, 42-45 (2014)

10. R. Kunze, B. Scharte, M. Bartholmai, D. Neubert, R. Schriever. Journal of thermal analysis and calorimetry, 3, 901-913 (2002)

11. K. Langille, D. Nguyen, D. Veinot. Fire technology, 2, 99-110 (1999)

12. M. Heinisuo, M. Laasonen, J. Outinen, J. Hietaniemi. Application of Structural Fire Design, 405$410(2011)$

13. M. Gravit, V. Gumenyuk, O. Nedryshkin. Procedia Engineering, 117, $114-118$ (2015)

14. A. Krivtcov, V. Kazakova, I. Mingalimov, P. Bogdanov, I. Nitsa. Construction of Unique Buildings and Structures, 6(33), 34-46, (2015)

15. M. Lazarevska, M. Knežević, M. Cvetkovska, A. Trombeva-Gavriloska, Tehnicki Vjesnik, 21 (6), 1353-1359 (2014)

16. O. Halyavin, M. Gravit, A. Pryanikova. Science Week STU, 22-25 (2015)

17. M. Lazarevska, M. Milanović, M. Knežević, M. Cvetkovska, A.T. Gavriloska, T. Samadzioska, Journal of Applied Engineering Science, 12 (1), 63-68 (2014)

18. Y. Dong, G. Wang, J. Yang. JCT Research, 2, 231-237 (2014)

19. P. Kraus, M. Mensinger, F. Tabeling, P. Schaumann. Journal of Structural Fire Engineering, 6, 237-246 (2015)

20. Z. Arabasadi, M. Khorasani, S. Akhlaghi, H. Fazilat, U. Gedde, M. Hedenqvist, M. Shiri. Fire Safety Journal, 61, 193-199 (2013)

21. M. Salminen, M. Heinisuo. Journal of Constructional Steel Research, 97, 105-113 (2014)

22. R. Puri, A. Khanna. Progress in Organic Coatings, 92, 8-15 (2016) 